\title{
Role of interleukin -6 (IL-6) in evaluating surgical stress after total abdominal hysterectomy (TAH) and non - descent vaginal hysterectomy (NDVH)
}

Ashraf Nassif Mahmoud Elmantwe' \& Ayman Asaad Ibrahim²

Department of Obstetrics and Gynecology,

Benha University Hospital, Banha University

${ }^{2}$ Department of Microbiology\& immunology, Faculty of medicine, Ain Shams University
Corresponding author: Ashraf Nassif Mahmoud Elmantwe

Department of Obstetrics and Gynecology,

Benha University Hospital, Banha University

ashrafnassif2002@yahoo.com.

$+01001801244$

\section{$\underline{\text { Abstract }}$}

Aim: to compare surgical stress between (TAH) and (NDVH) in women whom hysterectomy is indicated for benign disease by perioperative inflammatory response using interleukin-6 (IL6) and perioperative clinical outcomes.

Patients \& Methods: Twenty patients with benign uterine disease and failed medical treatment with uterine size $\leq 12$ weeks were randomized into two equal group for either TAH or NDVH. Serum levels of IL6 In venous blood were analyzed preoperatively and 3, 24,72 hour after beginning of surgery. Intraoperative, postoperative clinical outcome measure and surgery related morbidity were also, evaluated in both groups. Statistical analysis was done using medcalc software bvba 2016.

Results: There was no statistically significant difference present in demographic characteristics, operative duration and uterine weight between TAH and NDVH groups. No major complications were occurred. There was statistically significant increase in serum IL6 level from preoperative value to the 3 hours value after beginning of surgery in TAH group when compared with NDVH group, indicating greater tissue trauma in TAH group. There was statistically significant results in favour of NDVH over TAH as regards hospital stay, pain score, need for analgesia, wound infection, recuperation time $(\mathrm{P}<0.05)$.

Conclusion: NDVH is better than TAH for uteri less than 12 weeks in terms of perioperative inflammatory response and clinical outcome measures.

Keywords: NDVH, TAH, surgical trauma, IL6.

\section{Abbreviations:}

$\begin{array}{ll}\text { A H } & \text { Abdominal hysterectomy } \\ \text { IL6 } & \text { Interleukin.6 } \\ \text { LAVH: } & \text { Laparoscopic assisted Vaginal hysterectomy } \\ \mathbf{L H} & \text { Laparoscopic Hysterectomy } \\ \text { NDVH: } & \text { Non Descent vaginal } \\ \boldsymbol{T A H}: & \text { Total abdominal hysterectomy } \\ \boldsymbol{T L H} & \text { Total Laparoscopic hysterectomy } \\ \boldsymbol{V H} & \text { vaginal hysterectomy }\end{array}$

\section{Introduction}

Hysterectomy is the most common major gynecological surgery done worldwide; it is only second to caesarean section ${ }^{(1)}$. Hysterectomy, for benign uterine diseases, could be done either abdominal (AH), vaginal $(\mathrm{VH})$ or laparoscopic $(\mathrm{LH})^{(2)}$. Despite the randomized studies that have demonstrated better clinical outcomes and less surgical trauma after VH and $\mathrm{LH}$ in comparison to $\mathrm{AH}$, the most common route used for hysterectomy worldwide is still abdominal ${ }^{2}$. 
Surgical tissue trauma is a trigger for acute-phase reactants (APR) which is considered to be induced by cytokines such as $\mathrm{C}$-reactive protein (CRP), tumor necrosis factor $\alpha(\mathrm{TNF} \alpha)$ and interleukin -6 (IL-6) ${ }^{(3)}$. Serum IL-6 as a marker for inflammatory response is relatively easy to measure and has been shown to correlate well with the severity of trauma, amount of blood loss, length of operative time, extent of laparotomy incision ${ }^{(4)}$. In relation to the other available inflammatory markers, IL6 correlates best with the magnitude of surgical trauma and the systemic inflammatory response ${ }^{(5)}$.

Several trials have compared the extent of surgical trauma between the alternative routes of hysterectomy $\mathrm{AH}, \mathrm{VH}$ and $\mathrm{LH}$. Authors have found that surgical trauma and inflammatory response are more marked after $\mathrm{AH}$ than after $\mathrm{VH}$ or $\mathrm{LH}^{(6-17)}$.

However fewer studies have compared TAH to NDVH by perioperative IL- 6 and clinical outcomes in group of women with uteri $\leq 12$ weeks.

Therefore in this study we examined the differences in surgical tissue trauma between the TAH and NDVH by perioperative measuring IL-6 and perioperative clinical outcome measures

\section{Patients and Methods}

This was a prospective randomized study carried out at Benha university hospital from April 2015 to March 2016. Patients were recruited from the gynecological outpatient clinic. Local ethics committee approval of the study and written informed consent were obtained from all study participants.

A complete clinical history was taken and a detailed physical examination was performed and also, all women underwent preoperative endometrial biopsy and transvaginal ultrasound. Woman with benign uterine pathology indicated for hysterectomy with uterine size $\leq 12$ weeks were included in the study.

Patients with medical diseases, recent trauma or systemic infections that might result in altered inflammatory reaction to surgery were excluded. Women with genital malignancy, acute pelvic inflammatory disease, uterovaginal descent greater than first degree, uterine size $>12$ weeks, prior pelvic surgery, BMI $>35 \mathrm{~kg} / \mathrm{m} 2$, narrow vagina and necessity for another concomitant surgery were also excluded. Women eligible to participate were instructed to be off any anti-inflammatory drug and physical exercise at time of enrollment.

The minimum sample size to detect a difference of one standard deviation between IL-6 level of the two groups, with type I error of 0.01 and power of $80 \%$ was calculated to be 10 patients to be operated in each group. So, a sample of 20 women was needed for the present study. Enrolled women were randomized into either TAH group or NDVH group by closed envelopes method

In NDVH group, incision was made in cervicovaginal junction all around the cervix. Bladder was pushed up, vesico-uterine pouch was opened anteriorly and Douglas pouch was opened posteriorly. Then uterosacral cardinal ligaments, uterine vessels followed by round and ovarian ligaments and fallopian tubes were clamped, cutted and ligated. Finally the peritoneum and vaginal cuff were closed.

In TAH group, through a PFannestiel incision extrafascial total hysterectomy was performed by clamping, cutting and ligation of round, ovarian ligaments and fallopian tubes then uterine vessels followed by cardinal and uterosacral ligaments. Then the peritoneum (both visceral and parietal) vaginal cuff and abdominal wall were closed in layers.

All procedures were done by the same surgical team and carried out under general anesthesia with endotracheal intubation. All women received the same antibiotic prophylaxis intravenously preoperatively and the same preoperative medication. Diathermy was used only for hemostasis and intraperitoneal drain was left in both groups as folly's catheter in NDVH or protovac in TAH.

Venous blood samples from all women were drawn preoperatively and at 3,24,72 hours after beginning of surgery. Serum was isolated and stored at $-70^{\circ} \mathrm{c}$. Using standard IL-6 solution with known concentration of IL-6 in $\mathrm{pg} / \mathrm{ml}$, optical density at $420 \mathrm{~nm}$ was determined. Serum IL-6 level estimation was assessed using human IL6 ELISA kit supplied by Biosupply UK using quantitative sandwich immunoassay.

The main laboratory outcome was the mean difference in IL-6 level in the TAH and NDVH groups as measured postoperatively and preoperatively.

The main clinical outcome measures were: 1) Operative time (from skin or vaginal incision to closure), 2) Operative blood loss (was estimated subjectively, based on number and weight of gauze towel used where weight difference in grams transformed into blood loss in $\mathrm{ml}), 3$ ) Decline in hemoglobin value was measured 24 hours after end of the procedure, 4) Operative complications as blood transfusion, conversion in case of NDVH or relaparotmy in TAH, bowel or visceral injuries, 5) Early postoperative follow up including : 
(a) hospital stay, (b) Postoperative pain was assessed at 6, 24 hours for patients by visual analogue scale (VAS), a graduated $100 \mathrm{~m}$ line ranging from 0 (no pain) to $100 \mathrm{~mm}$ (pain as bad as it could be), patients were subdivided into five categories: absence of pain $($ VAS $=0)$, mild pain (VAS 1-25). Moderate pain $(\mathrm{VAS}=26-50)$, severe pain $(\mathrm{VAS}=51-75)$, and very severe pain (VAS $=76-100$ ), (c) Febrile morbidity (body temperatures $\geq 38 \mathrm{C}^{\mathrm{O}}$ in two consecutive measurements $\geq 4$ hour apart), (d) Need for analgesia "women included in present study were not given routine postoperative analgesia", (e) Time to pass stool or gas from end of the procedures, f) Time to get out of bed activity (hours). 7) Remote postoperative follow up, for up to 3 months, includes recuperation time and postoperative vaginal length.

Statistical analysis was performed by Medcalc easyto-use statistical software for windows desktop (www. medcalc.org) 2016 (Medcalc, software, bvba). Two sample t test was used to camper continuous variables baseline characteristics, operative time, blood loss, ileus time postoperative, body temperature, time to get of bed activity, hospital stay, recuperation time and serum interleukin 6 levels between the two groups. Categorical variables were presented as number and percentage and were assisted using Fisher's exact test. A P $<0.05$ was considered statistically significant.

\section{$\underline{\text { Results }}$}

A total of twenty women were included and statistically analyzed in the present study, 10 women in TAH group and 10 women in NDVH group.

There was no statistical difference between the two groups regarding age, parity, body mass index, clinical uterine size, ultrasound uterine volume, postoperative uterine weight as in (table I).

The main indication for hysterectomy was failure of medical treatment for peri-menopausal bleeding
(PMB) 60\%, endometrial hyperplasia (EH) 25\%, cervical intraepithelial neoplasia (CIN) 15\% and there were no difference between both groups.

All women were analyzed for intra-operative and postoperative clinical outcomes, blood loss and operative time were not significantly different between the two groups (table 2) and no major intra-operative complications were occurred. Postoperative pain score at 6,24 hour and need for analgesia were significantly less in NDVH group (table 3 ). Women included in this study were not given routine postoperative analgesia. All women $10(100 \%)$ in TAH group were expressed moderate to severe pain at 6 hours and 24 hour postoperative that demanded analgesia and were given, this is compared to 6 women $(60) \%$ who expressed moderate pain in NDVH group and demanded analgesia at 6 hour postoperative as in (table 3 ).

There were significant difference in favor of NDVH over TAH in terms of shorter time to first postoperative flatus, shorter time to get out of bed activity, shorter hospital say, shorter recuperation period, presence of abdominal scare, while no difference in decline of hemoglobin, febrile morbidity, vaginal length as in (table 4).

Serum IL-6 levels were estimated preoperatively (IL$6_{\mathrm{p}}$ ) and after beginning of surgery at 3 hour (IL-6 $\left.6_{3}\right), 24$ hour (IL-6 $\left.{ }_{24}\right)$ and 72 hour (IL-6 $6_{72}$ ).

Serum IL-6 levels Peaked at 3 hour after beginning (IL-6 ${ }_{3}$ ) and gradually returned to there baseline value as in (table 5).

The serum level of IL-6 and the differences between preoperative and 3, 24, 72 hours after beginning surgery showed that hysterectomy whether performed abdominally or vaginally was associated with a significant stress response. This response was marked with abdominal approach when compared to vaginal approach, suggesting the tissue trauma were less in NDVH than TAH as in (Table 5, 6). 
Table 1: Demographics and clinical characteristics of patients underwent TAH and NDVH.

\begin{tabular}{|l|c|c|c|c|c|c|c|}
\hline \multirow{2}{*}{ Variable } & \multicolumn{3}{c|}{ TAH (n=10) } & \multicolumn{3}{c|}{ NDVH (N=10) } & P valve \\
\hline & Mean & SD & Range & Mean & SD & Range & \\
\hline Age & 46.5 & 5.2 & $43-52$ & 47.6 & 4.9 & $44-53$ & 0.63 \\
\hline Parity & 2.9 & 1.5 & $0-5$ & 3.1 & 1.3 & $0-6$ & 0.75 \\
\hline BMI (kg/m ${ }^{2}$ ) & 27.5 & 2.4 & $25.5-30.5$ & 28.5 & 2.6 & $26.2-30.5$ & 0.38 \\
\hline Clinical uterine size (weeks) & 9.2 & 1.9 & $6-12$ & 9.5 & 1.8 & $6-12$ & 0.72 \\
\hline Ultrasound uterine volume (mL) & 85 & 20 & $55-120$ & 90 & 25 & $60-130$ & 0.62 \\
\hline Postoperative uterine weight (gram) & 90 & 25 & $60-130$ & 95 & 30 & $60-135$ & 0.69 \\
\hline Indication for Hysterectomy: & \multicolumn{2}{|c|}{ No } & & & & & \\
\hline
\end{tabular}

$\mathbf{P}<\mathbf{0 . 0 5}$ : Statistically significant. PMB perimenopasual bleeding, CIN Cervical intraepithelial neoplasia, EH endometrial hyperplasia, NDVH: non descent vaginal Hysterectomy, TAH total abdominal Hysterectomy.

Table 2: Comparison of intraoperative outcome measures between TAH and NDVH groups.

\begin{tabular}{|c|c|c|c|c|c|c|c|}
\hline \multirow[t]{2}{*}{ Outcome } & \multicolumn{3}{|c|}{ TAH $(n=10)$} & \multicolumn{3}{|c|}{$\operatorname{NDVH}(n=10)$} & \multirow[t]{2}{*}{ P valve } \\
\hline & Mean & SD & Range & Mean & SD & Range & \\
\hline Operative time ( $\mathrm{min}$ ) & 75 & 20 & $60-100$ & 80 & 25 & $65-110$ & 0.62 \\
\hline \multirow[t]{2}{*}{ Blood loss $(\mathrm{ml})$} & 250 & 175 & $150-500$ & 275 & 150 & $150-500$ & 0.73 \\
\hline & \multicolumn{2}{|c|}{ No } & $\%$ & \multicolumn{2}{|c|}{ No } & $\%$ & \\
\hline Operative complication & \multicolumn{2}{|c|}{0} & $(0 \%)$ & \multicolumn{2}{|c|}{0} & $(0 \%)$ & \\
\hline
\end{tabular}

$\mathbf{P}<\mathbf{0 . 0 5}$ : Statistically significant. SD: Standard deviation, TAH: Total abdominal hysterectomy,

NDVH : Nondescent vaginal hysterectomy. 
Table 3: Comparison of pain score and need for analgesia between TAH and NDVH groups.

\begin{tabular}{|c|c|c|c|c|c|c|c|}
\hline \multirow{2}{*}{$\begin{array}{c}\text { Outcome } \\
\text { Pain score }\end{array}$} & \multicolumn{3}{|c|}{ TAH $(n=10)$} & \multicolumn{3}{|c|}{ NDVH $(n=10)$} & \multirow[t]{2}{*}{ P valve } \\
\hline & No & & $\%$ & No & & $\%$ & \\
\hline \multicolumn{8}{|l|}{ a) at $6 \mathrm{~h}$} \\
\hline - Mild & 0 & & $0 \%$ & 4 & & 40 & 0.02 \\
\hline - Moderate & 2 & & $20 \%$ & 6 & & $60 \%$ & 0.07 \\
\hline - Severe & 8 & & $80 \%$ & 0 & & 0 & 0.0004 \\
\hline -Very severe & 0 & & 0 & 0 & & 0 & - \\
\hline \multicolumn{8}{|l|}{ b) at $24 \mathrm{~h}$} \\
\hline - Mild & 0 & & $0 \%$ & 6 & & $60 \%$ & 0.004 \\
\hline - Moderate & 2 & & $20 \%$ & 4 & & $40 \%$ & 0.34 \\
\hline - Severe & 8 & & $80 \%$ & 0 & & 0 & 0.0004 \\
\hline -Very severe & 0 & & 0 & 0 & & 0 & \\
\hline \multicolumn{8}{|l|}{ Need for analgesia } \\
\hline a) at $6 \mathrm{~h}$ & 10 & & $100 \%$ & 6 & & $40 \%$ & 0.029 \\
\hline \multirow[t]{2}{*}{ b) at $24 \mathrm{~h}$} & 10 & & $100 \%$ & 4 & & $(40 \%)$ & 0.004 \\
\hline & Mean & $\mathrm{SD}$ & Range & Mean & SD & Range & \\
\hline c) Days after Surgery & 10.3 & 5.2 & $3-20$ & 3.4 & 1.5 & $(0-5)$ & 0.0008 \\
\hline
\end{tabular}

$\mathbf{P}<\mathbf{0 . 0 5}$ : Statistically significant. SD: Standard deviation, TAH: Total abdominal hysterectomy,

NDVH : Nondescent vaginal hysterectomy.

Table 4: Comparison of early and late postoperative outcome measures between TAH and NDVH groups.

\begin{tabular}{|c|c|c|c|c|c|c|c|}
\hline \multirow[t]{2}{*}{ Variable } & \multicolumn{3}{|c|}{ TAH $(n=10)$} & \multicolumn{3}{|c|}{ NDVH $(\mathbf{N}=10)$} & \multirow[t]{2}{*}{ P valve } \\
\hline & Mean & SD & Range & Mean & $\mathrm{SD}$ & Range & \\
\hline 1- Time to get out of bed activity (h) & 20.5 & 5.6 & $8-30$ & 9.6 & 2.8 & $3-10$ & $<0.0001$ \\
\hline 2- Time of first postoperative flatus(h) & 36.2 & 4.5 & $12-48$ & 9.5 & 2.3 & $16-18$ & $<0.0001$ \\
\hline 3-Decline in hemoglobin at $24 \mathrm{~h}(\mathrm{~g} / \mathrm{dl})$ & 1.1 & 0.6 & $0.5-1.8$ & 0.9 & 0.7 & $0.6-1.7$ & 0.50 \\
\hline 4- Hospital stay (h) & 60.5 & 8.5 & $48-96$ & 36.2 & 7.5 & $24-48$ & $<0.0001$ \\
\hline 5-Recuperation (day) & 22.5 & 5.4 & $15-30$ & 10.6 & 4.6 & $7-15$ & $<0.001$ \\
\hline \multirow[t]{2}{*}{ 6- Postoperative vaginal length } & 9 & 0.7 & $8-10$ & 8.5 & 0.8 & $8-10$ & 0.15 \\
\hline & \multicolumn{2}{|c|}{ No } & $\%$ & \multicolumn{2}{|c|}{ No } & $\%$ & \\
\hline 7- Febrile morbidity & \multicolumn{2}{|c|}{1} & $10 \%$ & \multicolumn{2}{|c|}{1} & $10 \%$ & 1 \\
\hline 8- Vaginal spotting & \multicolumn{2}{|c|}{3} & $30 \%$ & \multicolumn{2}{|c|}{3} & $30 \%$ & 1 \\
\hline 9- Wound infection & \multicolumn{2}{|c|}{2} & $20 \%$ & \multicolumn{2}{|c|}{0} & $0 \%$ & 0.02 \\
\hline 10- Abdominal scare & \multicolumn{2}{|c|}{10} & $100 \%$ & \multicolumn{2}{|c|}{0} & $0 \%$ & $<0.0001$ \\
\hline
\end{tabular}

$\mathbf{P}<\mathbf{0 . 0 5}$ : Statistically significant. SD: Standard deviation, TAH: Total abdominal hysterectomy,

NDVH : Nondescent vaginal hysterectomy. 
Table 5: Comparison of IL-6 between TAH and NDVH groups

\begin{tabular}{|c|c|c|c|c|c|}
\hline Serum IL-6 (ng/ml) & \multicolumn{2}{|c|}{ TAH $(n=10)$} & \multicolumn{2}{|c|}{ NDVH $(n=10)$} & $P^{\text {a }}$ valve \\
\hline & Mean & SD & Mean & SD & \\
\hline IL-6 ${ }_{p}$ & 0.255 & 0.311 & 0.244 & 0.223 & 0.92 \\
\hline IL-6 $_{3}$ & 0.832 & 0.422 & 0.455 & 0.166 & 0.017 \\
\hline$P^{\mathrm{b} 1}$ value & \multicolumn{2}{|c|}{0.0027} & \multicolumn{2}{|c|}{0.027} & - \\
\hline IL-6 $_{24}$ & 0.532 & 0.231 & 0.351 & 0.135 & 0.046 \\
\hline $\mathbf{P}^{\mathrm{b}^{2}}$ value & \multicolumn{2}{|c|}{0.036} & \multicolumn{2}{|c|}{0.22} & - \\
\hline IL-6 $_{72}$ & 0.462 & 0.242 & 0.264 & 0.171 & 0.048 \\
\hline$P^{b 3}$ value & \multicolumn{2}{|c|}{0.11} & \multicolumn{2}{|c|}{0.82} & - \\
\hline
\end{tabular}

$\mathbf{P}<\mathbf{0 . 0 5}$ : Statistically significant. IL-6 $\mathbf{b}_{\mathrm{p}}$ : Preoperative value. IL-6 $\mathbf{3}: 3 \mathrm{~h}$ after beginning of surgery value. IL-6 $\mathbf{6}_{24}: 24 \mathrm{~h}$ after beginning of surgery value. IL-6 $\mathbf{6}_{72}: 72 \mathrm{~h}$ after beginning of surgery value. SD: Standard deviation, TAH: Total abdominal hysterectomy. NDVH : Nondescent vaginal hysterectomy, $\mathbf{P}^{\mathbf{a}}$ : Comparison between the both groups TAH and NDVH. $\mathbf{P}^{\mathbf{b}}$ : Comparison between the preoperative IL-6 and the postoperative IL-6 in the same group, $\mathbf{P}^{\mathrm{b} 1}$ : With IL- $6_{3}, \mathbf{P}^{\mathbf{b} 2}$ : with IL- $6_{24}, \mathbf{P}^{\mathbf{b} 3}$ : with IL-6 ${ }_{72}$

Table 6: Comparison of serum Il-6 difference between TAH and NDVH groups

\begin{tabular}{|l|l|c|c|c|c|}
\hline $\begin{array}{c}\text { Difference in IL-6 } \\
\text { Level (ng/ml) }\end{array}$ & \multicolumn{2}{|c|}{ TAH (mean) } & \multicolumn{2}{c|}{ NDVH } & P valve \\
\hline & Mean & SD & Mean & SD & \\
\hline IL-6 $_{\mathbf{3}}-$ IL-6 $_{\mathbf{p}}$ & 0.577 & 0.418 & 0.211 & 0.158 & 0.018 \\
\hline IL-6 $_{24}-$ IL-6 $_{\mathbf{p}}$ & 0.277 & 0.241 & 0.087 & 0.125 & 0.040 \\
\hline IL-6 $_{72}-$ IL-6 $_{p}$ & 0.207 & 0.231 & 0.020 & 0.181 & 0.059 \\
\hline
\end{tabular}

$\mathbf{P}<\mathbf{0 . 0 5}$ : Statistically significant. IL-6 $\mathbf{6}_{\mathrm{p}}$ : Preoperative value, IL-6 $_{3}: 3 \mathrm{~h}$ after beginning of surgery value, IL-6 $_{24}: 24 \mathrm{~h}$ after beginning of surgery value, IL-6 $\mathbf{6}_{72}: 72 \mathrm{~h}$ after beginning of surgery value. TAH: Total abdominal hysterectomy.

NDVH : Nondescent vaginal hysterectomy, 


\section{Discussion}

The present study shows that both TAH and NDVH are associated with significant surgical stress response in term of objective parameter of surgical trauma, as IL-6 was found to increase rapidly after surgery and peaked between 3 and 24 hour after beginning of surgery, then came to baseline in 72 hour. This results are similar to results of other studies, that investigate serum IL-6 in nongynecological surgeries, such as open and laparoscopic appendectomy, cholecystectomy, colectomy, nephrectomy ${ }^{(18,19,20)}$.

Also, these results are in agreement with other trials that investigate immune response to abdominal, vaginal, laparoscopic hysterectomy ${ }^{(8,14,16,17)}$.

The current study demonstrates that, the surgical trauma was maximal with TAH than $\mathrm{NDVH}$, as the difference of serum IL- 6 between 3 hour after beginning of surgery (IL-6 ${ }_{3}$ ) and preoperative (IL-6 was statistically significant, this results is like that reported by Aka et al. ${ }^{(8)}$,Yuen et al. ${ }^{(11)}$, Malik et al. ${ }^{(14)}$, Holub et al. ${ }^{(15)}$, Roy et al. ${ }^{(16)}$, Osksuzoghn et al. ${ }^{(17)}$.

Aka et al., prospectively compared abdominal hysterectomy to vaginal hysterectomy with colporrhaphy by perioperative $\alpha 1$-Antitirypsin, CRP, myoglobulin and found that tissue trauma was maximal with AH. They concluded that, whenever possible, VH should replace $\mathrm{AH}^{(8)}$.

Malik et al., prospectively compared perioperative IL-6 and CRP with AH, VH, LAVH and they stated that the peaked IL-6 after AH might reflect significant greater tissue damage. They recommended that LAVH should therefore be considered in cases that cannot be managed by the vaginal route alone ${ }^{(14)}$.

Holub et al., compared tissue damage from alternative routes of hysterectomy by serum CRP and creatine kinase $(\mathrm{CK})$. The authors founded significant increase in serum $\mathrm{CK}$ and CRP in $\mathrm{AH}$ than $\mathrm{VH}$ or $\mathrm{LH}$ groups. They concluded that tissue damage is more in $\mathrm{AH}$ than $\mathrm{VH}$ or $\mathrm{LH}^{(15)}$.
Roy et al., compared surgical stress by perioperative serum IL-6 after LAVH and NDVH for large uterine. he authors found that, the surgical stress was major in LAVH group and concluded that NDVH should be the first choice for large uteri ${ }^{(16)}$.

Oksuzoglu et al., compared tissue trauma after $\mathrm{AH}$, $\mathrm{VH}$ and TLH by perioperative IL6 and CPK "creatine phosphokinase", the authors found more tissue trauma with $\mathrm{AH}$ than with $\mathrm{VH}$ or TLH but they considered the TLH is better in term of postoperative clinical outcomes ${ }^{(17)}$.

This study, as regards the perioperative clinical outcomes found that, there is no difference in demographic profile of the patients between the TAH and NDVH groups as regards age, parity, BMI, uterine size, uterine volume. Also, the intraoperative clinical measures were comparable in both groups. While the postoperative outcomes were in favour of NDVH over TAH regards time to get out of bed activity, time to first flatus, pain scare, need for analgesia, hospital stay, and recuperation time. These results are in agreement with Aka et al., Yuen et al., Malik et al., Holub et al., Ray et al., Oksuzogln et al. ${ }^{(8,11,14,15,16,17) .}$

In NDVH, the vagina is the access point while, in TAH the access is through anterior abdominal wall, so in TAH there is superadded trauma of opening and closing anterior abdominal wall over the usual trauma that needed for total hysterectomy by any route. Also, there is excess is intestinal backing and manipulation in $\mathrm{AH}$ over NDVH. Both of this could justify the excessive increase in IL-6 (as an immune response to trauma) in women underwent TAH over than in women underwent NDVH and explain the better postoperative clinical outcomes in favor of NDVH over TAH.

\section{Conclusions}

From the present trial, we conclude that NDVH whenever possible should replace TAH because it is associated with less tissue damage and better postoperative clinical outcomes.

Conflict of interest: none 


\section{References}

1. Wu JM, Wechter ME, Geller EJ, Nquyen TV and Visco AG. Hysterectomy rates in the unites States, 2003. Obstet Gynecol. 2007; 110, 1091 - 1095.

2. Nieboer TE, Johnson N, Lethaby A, Tavender E, Curr E, Garry R, Van Voorst S, Mol BW and Kluvers KB. Surgical approach to hysterectomy for benign gynaecological disease. Cochrane Database Syst Rev 2009, (3): CD003677.

3. Ohzato H, Yoshizaki K, Nishimoto N, Ogata A, Tagoh H, Monden M, Gotoh M, Kishimoto T and Mori T. Interleukin- 6 as a new indicator of inflammatory status: detection of serum levels of Interleukin-6 and C-reactive protein after surgery. Surgery, 1992; 111: $201-209$.

4. Ishibashi S, Takeuchi H, Fujii K, Shiraishi N, Adachi $\mathbf{Y}$ and Kitano S. Length of laparotomy incision and surgical stress assessed by serum IL-6 level. Injury, 2006; 37: $247-251$.

5. Giannoudis PV, Smith RM, Evans RT, Bethany MC and Guillou PJ: Serum CRP and IL-6 levels after trauma: not predictive of septic complications. Acta Orthop Scand, 1995; 69: 184 -188.

6. Kim TK and Yoon JR. Comparison of the neuroendocrine and inflammatory responses after laparoscopic and abdominal hysterectomy. Korean J Anesthesiol. 2010; 59, 265 - 269.

7. Demir A, Bige O, Saatli B, Solak A, Saygili U and Onvural A. Prospective comparison of tissue trauma after laparoscopic hysterectomy types with retroperitoneal lateral transsection of uterine vessels using ligasure and abdominal hysterectomy. Arch Gynecol Obstet. 2008; 277: 325 - 330.

8. Aka N, Kose G, Gonenc I and Api M. Tissue trauma after vaginal hysterectomy and colporrhaphy versus abdominal hysterectomy: a randomized controlled study. Aust N Z J Obstet Gynecol. 2004; 44: 328 - 331.

9. Atabekoglu C, Sonmezer M, Gungor M, Aytac R, Ortac F, Unlu C. Tissue trauma in abdominal and laparoscopic - assisted vaginal hysterectomy. J Am Assoc Gynecol Laparosc. 2004, 11: 467 - 472.

10. Harkki-Siren $P$, Sjoberg $J$, Toivonen $J$ and Titinen A. Clinical outcome and tissue trauma after laparoscopic and abdominal hysterectomy: a randomized controlled study. Acta Obstet Gynecol Scand., 2000; 79: 868-871.
11. Yuen PM, Mak TW, Yim SF, Ngan Kee WD, Lam CW, Rogers MS and Chang AM. Metabolic and inflammatory responses after laparoscopic and abdominal hysterectomy. Am J Obstet Gynecol., 1998, 179: 1-5.

12. Labib M, Palfrey S, Paniagua E and Callender R. The postoperative inflammatory response to injury following laparoscopic assisted vaginal hysterectomy versus abdominal hysterectomy. Ann Clin Biochem. 1997; 34 (Pt 5): 543 - 545.

13. Ribeiro SC, Ribeiro RM, Santos NC and Pinotti JA. A randomized study of total abdominal, vaginal and laparoscopic hysterectomy. Int J Gynaecol Obstet. 2003; 83: $37-43$.

14. Malik E, Buchweitz O, Muller - Steinhardt M, Kressin P, Meyhofr-Malik A and Diedrich K. Prospective evaluation of the systemic immune response following abdominal, vaginal, and laparoscopically assisted vaginal hysterectomy. Surg Endosc. 2001; 15, 463 - 466.

15. Holub Z, Jabor A, Fischlova D and Palasek V. Tissue damage in alternative types of hysterectomy, prospective study. Ceska Gynekol. 1999; 64: 227 - 230.

16. Roy KK, Subbaiah M, Singla S, Sumar S, Sharma JB and Mitra DK. Role of serum interleukin-6 in comparing surgical stress after laparoscopic - assisted vaginal hysterectomy and non-descent vaginal hysterectomy for large uterine, Arch. Gynecol. Obstet. 2012; 285 : 671 - 676.

17. Osksuzogin A, Seckin B, Turkcapar AF, Ozcans and Gungor T. Comparison of tissue trauma after abdominal vaginal, total laproscopic hysterectomy: Ginekolpol. 2015; 86, $268-273$.

18. Juralowicz P, Czekalski P, Janiak $A$ and Modzelewski B. Postoperative inflammatory reaction in patients after open vs. laparoscopic gall bladder surgery. Clin Exp Med Lett Akad Med. 2009; 50(3): $183-186$.

19. Harmon GD, Senagore AJ, Kilbride MJ and Warzynski MJ. Interleukin-6 response to laparoscopic and open colectomy. Dis Colon Rectum, 1994; 37: 754 - 759.

20. Matsumoto ED, Margulis V, Tunc L, Taylor GD, Duchene D, Johnson DB, Pearle MS and Cadeddu JA. Cytokine response to surgical stress: comparison of pure laparoscopic, hand-assisted laparoscopic and open nephrectomy. J Endourol. 2005; 19: 9, 1140 - 1145 . 